\title{
Visualizing virtual users through art Usage statistics in outreach and marketing
}

\begin{abstract}
$\mathbf{M}$ ost modern academic libraries have physical and virtual spaces-and patrons. Physical users can be hard to miss, but virtual users often leave only traces behind. It's all too easy, and misleading, to assess library use based on bodies in chairs. While online resources provide statistics documenting use, these numbers may seem unreal to administrators and funding agencies. Western New Mexico University's Miller Library designed an art installation, "A Year of Virtual Research," as a large-scale physical data visualization project to make virtual library use more present and real to the university community.
\end{abstract}

\section{Virtual demand}

Western New Mexico University is a small, public, open-enrollment institution located in Silver City, New Mexico, in the southwest corner of the state. The gorgeous location features lots of resources, as the city sits high in the mountains and close to the Gila National Forest, but the area is rural and off the beaten track. An increasing percentage of students take online classes and nearly two-thirds of classes are partly or wholly online. In addition, as with many academic libraries, the shift towards digital and electronic resources allows on-campus users to access library resources without visiting the library in person.

\section{Honoring virtual research}

While the library works to attract physical users through a variety of means, staff want- ed to honor virtual research and users and make them more visible. The library has a history of art installations. Earlier in the century, student workers created more than 3,000 origami cranes to celebrate a grant of publications from the Nippon Foundation. A similar project a short while later featured large-scale orbs and butterflies commemorating the migration of butterflies across the state. Portions of these projects hang in the library to this day, an ongoing reminder and inspiration.

In May 2017, at the encouragement of Alea Henle, head of public services librarian, library staff decided to create a new installation organized around virtual use. Searches across library literature failed to identify examples for imitation. Most articles on art in libraries focused on library-as-host or, in a few cases, installations centered on other library services (e.g., information literacy). Nevertheless, the Miller staff aimed to highlight the extent of library support for, and use of, virtual services-specifically, to design, create, and hang the art by the start of the fall semester in mid-late August. Coincidentally, the New Mexico State Legislature's Interim Committee on Science, Technology,

Alea Henle, formerly of Western New Mexico University, is head of access and borrow at Miami University, email: alea.henle@gmail.com; Andrea Jaquez is public services supervisor, email: andrea.jaquez@wnmu.edu, and Hannah Gray is a student worker, email: grayh@wnmu. edu, both at Western New Mexico University

(c) 2018 Alea Henle, Andrea Jaquez, and Hannah Gray 
and Telecommunications scheduled a hearing in the library during the second week of classes, so having the work in place before they arrived became the goal.

\section{Data visualization}

Fortunately, Andrea Jaquez, public services supervisor, participated in the earlier installations and remembered creating the cranes from a pervious installation took six months. The hanging process likewise was a matter of weeks not days. Henle and Jaquez therefore set their sights lower numerically while still seek-

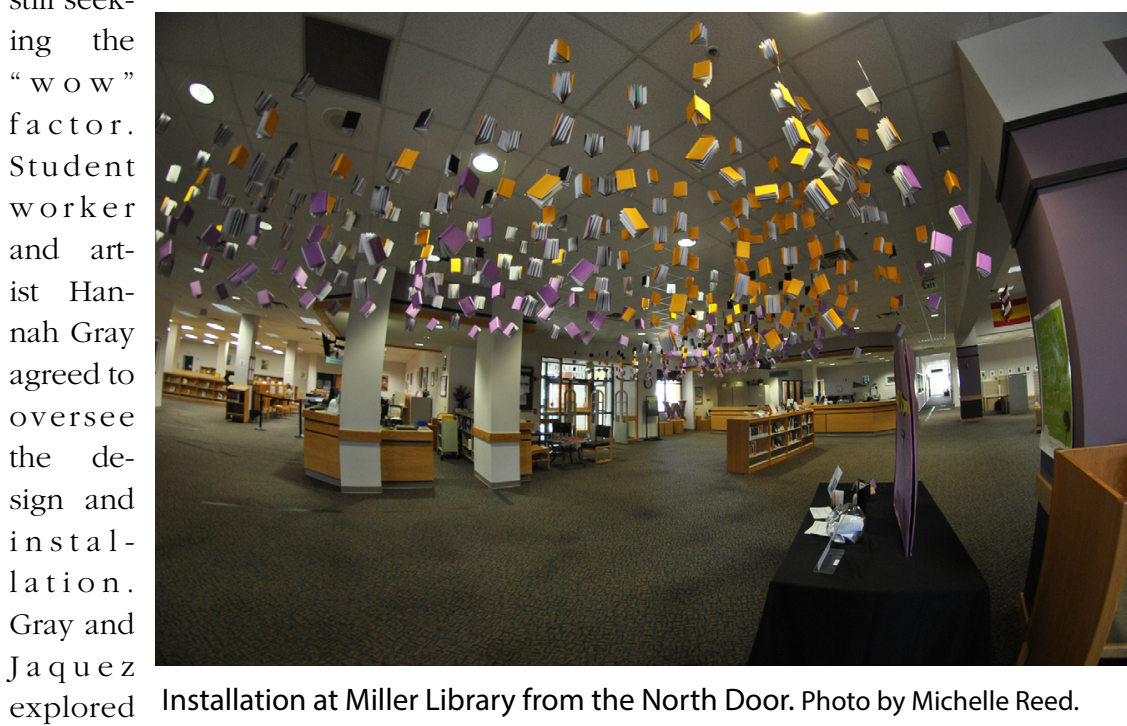

explored Installation at Miller Library from the North Door. Photo by Michelle Reed.

a variety

of formats. For instance, they considered featuring silhouettes of the university's mascot, the mustang. In the end, they settled on an origami book form as attractive and, of equal import, relatively simple to construct.

How many items should the installation feature? Selecting numbers required balancing competing interests. Organizers quickly decided to have the art represent a year of research (the most recent academic year), and to use search statistics. Despite efforts to standardize usage statistics, determining which numbers to use required more thought than initially anticipated. Few members of the university community or general public would likely notice or care about the different ways of counting use, but it mattered to the library staff. In the end, Henle and Jaquez used three different colors of covers to represent varying statistics. One color represented regular searches on databases and another federated searches across databases. These numbers drew from COUNTER-compliant reports and reflected platform, not database, searches so as not to over-count. A third color reflected searches on the library's discovery service, for which COUNTER-compliant numbers were not available. The original idea was to have each book represent 1,000 searches, but we subsequently amended this to make e a c h b o o k e qua 1 500 searches to better ensure $\mathrm{t} \mathrm{h} \mathrm{e}$ "WOW" factor.

A f ter setting the $\mathrm{n} \mathrm{u} \mathrm{m} \mathrm{-}$ bers in e a r 1 y J u $1 \mathrm{y}$, roughly six to seven weeks remained to develop and hang the installation. The scope of the project became clear early enough to allow ordering of colored paper in purple, gold, and black (the first two being the university colors). The origami books themselves were comprised of four sheets of paper. The interior of each book required three sheets of paper, for which staff plundered any and all recycling bins in the library. Student workers did the bulk of the assembly work while staffing the circulation desk in good time. As other students folded the interior pages, Gray took charge of the covers. After experimenting, she developed a technique for creating an enhanced spine with folds imitating the appearance of a hard-back book. 


\section{The OECD iLibrary platform recently had a major upgrade.}

The new version includes a number of significant improvements for users, such as:

- Faster and improved search functionality

- Modern and responsive design: desktop, tablet or mobile.

- More content in HTML

- Personal profile registrations to allow users to take advantage features such as tagging content, saving searches, and email alerts

The upgrade also takes effect on the following sites:

- The Commonwealth iLibrary

ITU iLibrary

- Nordic iLibrary

- UN iLibrary

For more information please email contact:

Iain Williamson

iain.williamson@OECD.org

202-822-3870

To receive emails in your area of interest please visit oe.cd/MyOECD 


\section{OECDiLibrary CONTAINS MORE THAN...}

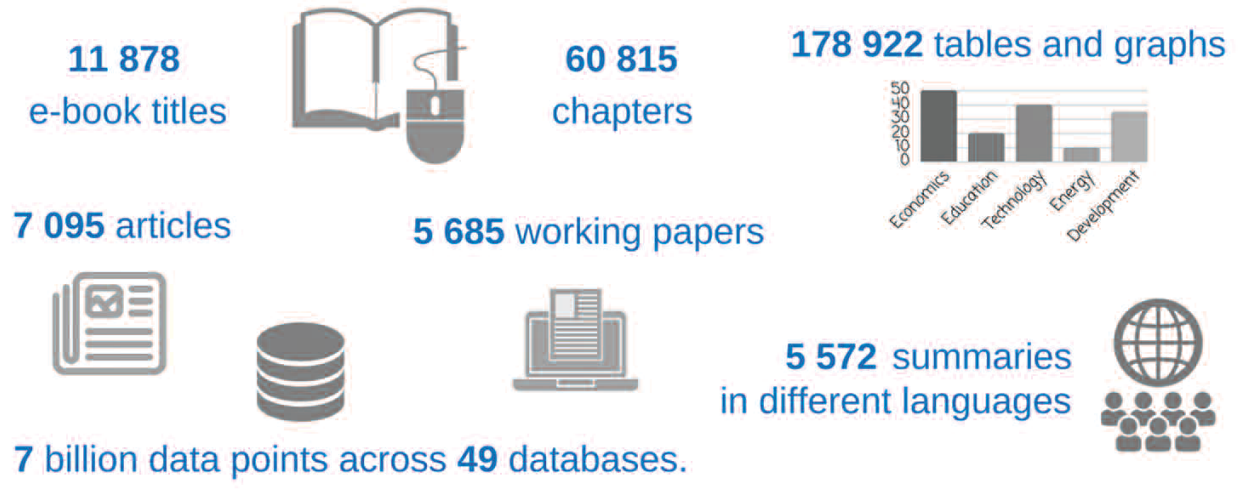

\section{How to use OECDiLibrary}

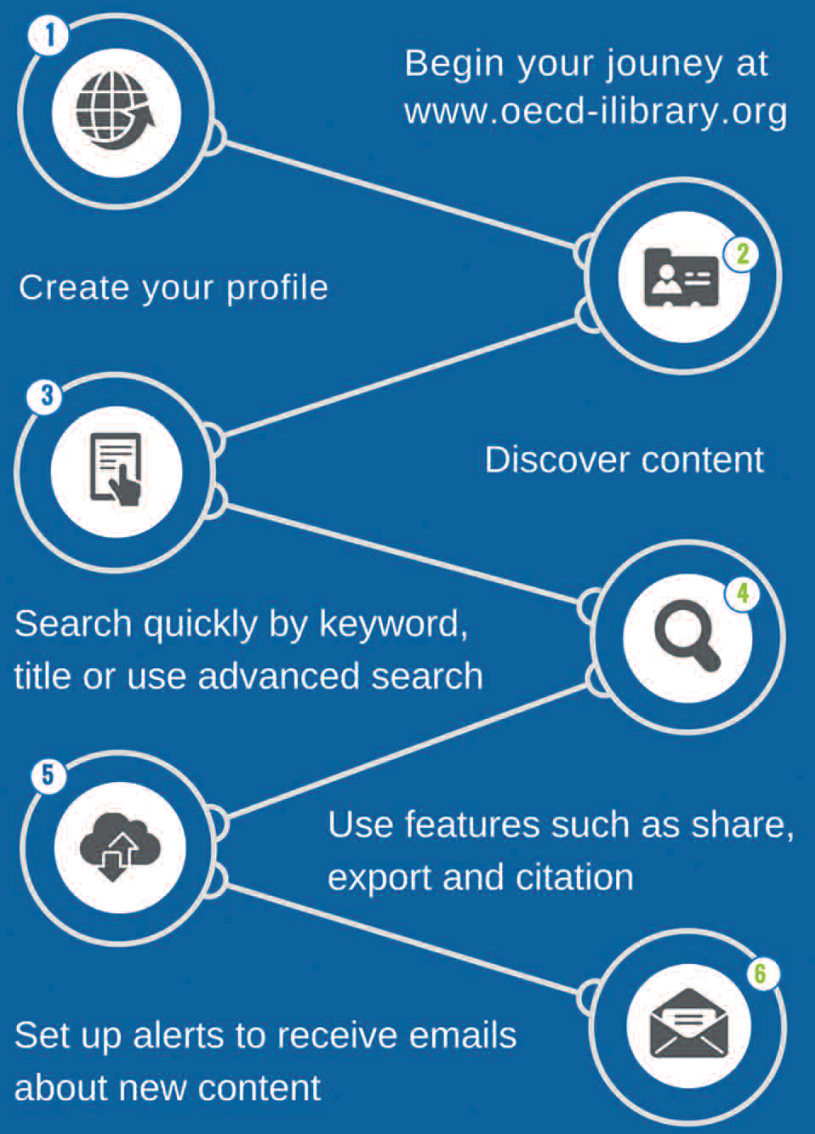




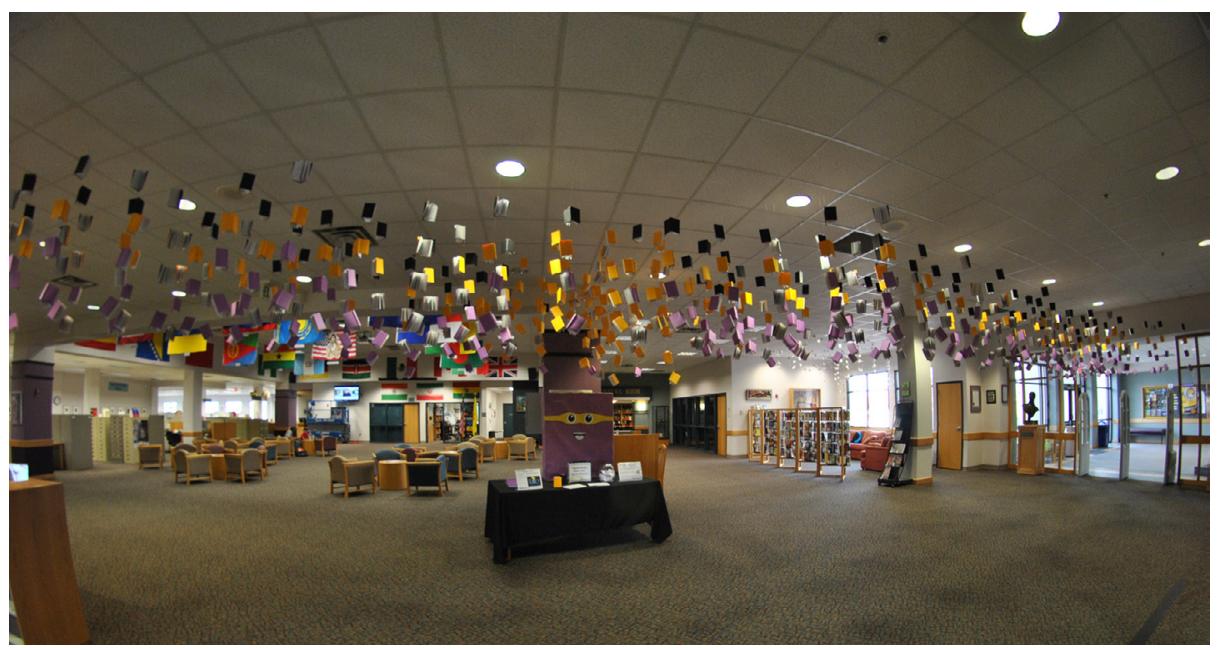

Installation at Miller Library from the East Door. Photo by Michelle Reed.

Assembling the books proved more complex than anticipated. After initial discussion, Gray and Jaquez determined it was best to glue the covers to the fishing line before gluing the interior pages. They created a sample strand of four books, using all three covers.

\section{Hannah's tips for data visualization art installations}

- Order sufficient construction paper for the covers to allow for experimentation.

- Don't go for thick construction paper, it doesn't bend well.

- Calculate how many you'll need of any element (individual interior pages, assembled interior pages, covers, etc.), and keep track of numbers as you go along.

- Attach the paperclips to the top book or other artifact to reduce the need to detangle strings at a later date.

- Don't pile the strands too high, the weight will flatten out the strands on the bottom.

- Don't be afraid to ask for help, because it's a big project.

- Adapt the design to the space to enhance the "wow" factor.
Gray advocated for use of stripes to take advantage of the different colors and create a flow to enhance the "wow" factor. Hanging the sample strand allowed us to determine how long to make them, and they were shortened to allow taller individuals to pass under without disturbance (although one or two particularly tall basketball players were later observed trying to avoid the strands altogether). Unfortunately, Gray proved allergic to something in the glue used on the fishing line, so other nonallergic students glued the strands to her specifications.

The actual installation took four hours on a Saturday morning before the semester started, during off hours. Each strand of fishing line had a large paperclip attached to the end. Gray inserted the paperclips under the ceiling tiles, allowing the weight of the tiles to hold the strands in place.

\section{An art installation}

After the initial installation, some patrons did not notice. In several instances, staff asked passersby if they liked the art and received a puzzled look. Patrons looked up and were visibly startled. They quickly embraced the work. "It's so pretty to walk in with them hanging," one wrote on a comment board. Other visitors praised the appearance and experience as "Beautiful 
and unique," "colorful and evocative," and "Loving how it looks!" (complete with two small hearts). Patrons also appreciated the use of recycled paper and "simple things to make a great art work." The university staff supporting online learning were particularly appreciative, turning out in force for the installation unveiling.

When dismantled, several strands of the installation will remain in the library or in the possession of library staff. Others may move to adorn the city more generally-a community member on the board of two local book-related organizations (a Friends group and the Southwest Festival of the Written Word) has expressed interest in using the remaining orig a m b o o k s. They may also reappear as an element in future conferences at the Miller Library. Thus, the orig a m i books will have a second life, repurposed

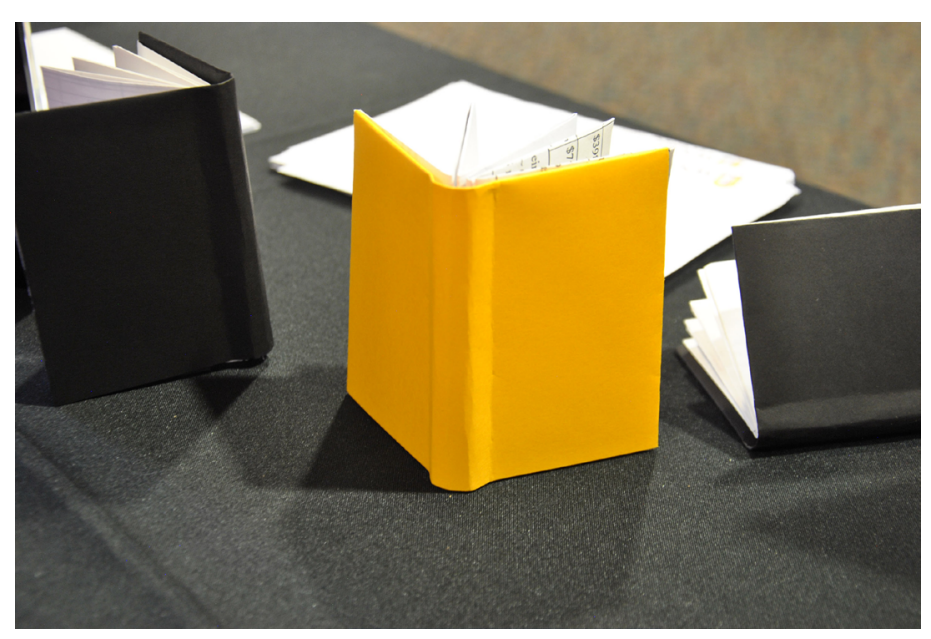

Book detail. Photo by Michelle Reed. progress.

\section{Lessons learned}

actual number, this nevertheless represents

If we went back in time to design and create this installation again, we would take a different approach with several aspects. First, we would make the installation unveiling event bigger, using a variety of ways (interesting speakers, food) to encourage larger attendance. Second, we would take it on the road, and explore measures to reach individuals who rarely or never set foot in the library, but use library resources, are aware of the installation and the scope of campus research. Possible ways to do this include a slide show, a mini or portable version of the installation, presentations to faculty b o d i e s (depart$\mathrm{ments}$, ge ne ral assembly, senate), and greatto promote reading and writing.

Reactions to the installation offer further evidence of the need to document and display the extent of virtual services. A contest accompanied the installation, challenging users to guess which month saw the highest number of searches and what that number was. Early guesses were on the low end: an administrator in the low four figures and a faculty member even lower at three figures. Henle called the latter to ask, politely, what were you thinking? Given encouragement, the faculty member decided to have more faith in the university community and submitted a second guess in the mid-upper five figure range. Although still 15,000 under the er outreach emphasizing numbers. Moreover, in retrospect the installation suffered mission drift. Initially we focused on helping the university community realize just how much they collectively use library resources, but by the unveiling, this went hand-in-hand with celebrating how much research the campus community conducts. Research celebration is important, and popular, but we wound up emphasizing it more than the high resource use, undercutting the latter's reach. Nevertheless, the installation was a big hit, worth the effort, and contributed to increased appreciation for library resources. 2 